\title{
Experimental Investigation of the Fire Resistance of Thin Hollow-Core Concrete Slabs with Simple Supports
}

\author{
Thanyawat Pothisiri* and Chaiyatorn Kositsornwanee \\ Department of Civil Engineering, Faculty of Engineering, Chulalongkorn University, Bangkok 10330, \\ Thailand \\ *E-mail: fcetps@eng.chula.ac.th (Corresponding author)
}

\begin{abstract}
This paper presents an experimental study on the fire resistance of relatively thin hollow-core concrete slabs with simple supports. A series of fire tests were conducted according to ISO 834 standard on nine hollow-core concrete slab specimens with thickness not exceeding $150 \mathrm{~mm}$. The key parameters investigated are the heating duration, slab thickness and load ratio. Based on the test results, it has been found that the fireresistance ratings of all the tested specimens fall below the specified requirements in the current building regulations of Thailand. The level of concrete spalling on the fire-exposed surface increases with the heating duration. It has also been found that the fire resistance of thicker hollow-core concrete slabs may be lower, even when smaller values of maximum vertical deflection are observed during the heating period. Furthermore, a higher load ratio leads to a more rapid collapse of the tested specimen. The experimental results suggest the necessity of supplementary means of fire protection for these slabs in practical building construction.
\end{abstract}

Keywords: Hollow-core concrete slabs, fire resistance, simple supports.

ENGINEERING JOURNAL Volume 19 Issue 2

Received 16 July 2014

Accepted 25 November 2014

Published 30 April 2015

Online at http://www.engj.org/

DOI:10.4186/ej.2015.19.2.139 


\section{Introduction}

Hollow-core concrete slabs have been widely used in the construction of buildings in many countries. The key advantage of hollow-core concrete slabs to typical cast-in-place slabs is the ease of installation. Hollowcore concrete slab units can be installed directly on the supporting beams with or without concrete topping and additional reinforcement. Moreover, because hollow-core concrete slabs are typically pre-cast in a controlled environment, the quality of the products can be assured. Despite these advantages, data from previous studies [1-7] suggest that the hollow-core concrete slabs may perform poorly under hightemperature conditions.

Previous studies [1-7] have reported several factors-i.e., concrete strength, water content, precompression force, concrete cover, aggregate type, load ratio and boundary condition-to affect the loadbearing performance of hollow-core concrete slabs under fire. The load-bearing capacity of hollow-core concrete slabs at elevated temperatures is generally governed by flexure, rather than shear. The flexural collapse of hollow-core concrete slabs has been indicated to be due to various factors, such as concrete spalling, transverse cracks and longitudinal cracks, leading to a premature rupture of the prestressing steel tendons [4].

At elevated temperatures, compression and tension zones on the cross sections of hollow-core concrete slabs may shift due to temperature gradients, and the temperature distribution may not be uniform through the thickness of the slabs due to the effect of air insulation inside the hollow cores [5-6]. The situation is further complicated for relatively thin hollow-core concrete slabs where the core configuration can also vary for slabs with different thicknesses. Thus far, the number of experimental studies on the fire resistance of relatively thin hollow-core concrete slabs is still limited. This study is aimed to examine the fire resistance of hollow-core concrete slabs with thickness not exceeding $150 \mathrm{~mm}$. A series of fire tests are conducted according to ISO834 standard on nine hollow-core concrete slab specimens with simple supports. The key parameters investigated are the heating duration, slab thickness and load ratio.

\section{Experimental Investigation}

\subsection{Test Specimens}

The test specimens were typical hollow-core concrete slabs manufactured by a local pre-cast concrete products company in Thailand under its quality control program. The summary of the test specimens are provided in Table 1. The dimensions of the specimens were $596 \mathrm{~mm}$ in width and $2300 \mathrm{~mm}$ in length. Note that the span length of the specimens was specified as governed by the dimensions of the furnace chamber.

Three values of thickness were examined, i.e. $100 \mathrm{~mm}, 120 \mathrm{~mm}$ and $150 \mathrm{~mm}$, respectively. The nominal concrete strength for the specimens was specified as $35 \mathrm{MPa}$ at 28 days. Each of the hollow-core concrete slabs was reinforced with six $4 \mathrm{~mm}$-diameter prestressing steel wires with a fixed concrete cover of $20 \mathrm{~mm}$. The ultimate tensile strength of the prestressing steel was $1850 \mathrm{MPa}$. The cross sections of the test specimens are illustrated in Fig. 1.

\subsection{Experimental Setup}

The fire tests were conducted at the Fire Safety Research Center (FSRC) of Chulalongkorn University. The details of the test setup can be described as follows.

\subsubsection{Furnace}

The internal dimensions of the furnace chamber were $2500 \mathrm{~mm}$ in length, $900 \mathrm{~mm}$ in width and $1700 \mathrm{~mm}$ in height prior to the installation of each hollow-core concrete slab. During the course of the fire test, the soffit of the hollow-core concrete slab was exposed to a specified heating condition inside the furnace chamber. The heating condition was controlled to follow the standard heating curve of ISO $834-1$ [8] by using two sets of three LPG-fueled nozzles, which are located at the heights of $500 \mathrm{~mm}$ and $1150 \mathrm{~mm}$ above the floor of the furnace. The temperatures inside the furnace chamber were monitored through six type-K thermocouples installed alongside the nozzles as illustrated in Fig. 2. 
Table $1 . \quad$ Summary of the test specimens.

\begin{tabular}{|c|c|c|c|c|c|c|}
\hline Specimen & $\begin{array}{l}\text { Width } \\
\text { (mm) }\end{array}$ & $\begin{array}{l}\text { Thickness } \\
\text { (mm) }\end{array}$ & $\begin{array}{l}\text { Length } \\
\text { (mm) }\end{array}$ & $\begin{array}{c}\text { Prestressing } \\
\text { Steel }\end{array}$ & Load Ratio & $\begin{array}{c}\text { Targeted } \\
\text { Heating } \\
\text { Duration } \\
\text { (min) }\end{array}$ \\
\hline HCT1 & 596 & 120 & 2300 & $6-\varnothing 4 \mathrm{~mm}$ & 0.3 & 30 \\
\hline НCT2 & 596 & 120 & 2300 & $6-\varnothing 4 \mathrm{~mm}$ & 0.3 & 60 \\
\hline HCT3 & 596 & 120 & 2300 & $6-\varnothing 4 \mathrm{~mm}$ & 0.3 & 90 \\
\hline HCL1 & 596 & 100 & 2300 & $6-\varnothing 4 \mathrm{~mm}$ & 0.3 & Until failure \\
\hline HCL2 & 596 & 100 & 2300 & $6-\varnothing 4 \mathrm{~mm}$ & 0.6 & Until failure \\
\hline HCL3 & 596 & 120 & 2300 & $6-\varnothing 4 \mathrm{~mm}$ & 0.3 & Until failure \\
\hline HCL4 & 596 & 120 & 2300 & $6-\varnothing 4 \mathrm{~mm}$ & 0.6 & Until failure \\
\hline HCL5 & 596 & 150 & 2300 & $6-\varnothing 4 \mathrm{~mm}$ & 0.3 & Until failure \\
\hline HCL6 & 596 & 150 & 2300 & $6-\varnothing 4 \mathrm{~mm}$ & 0.6 & Until failure \\
\hline
\end{tabular}

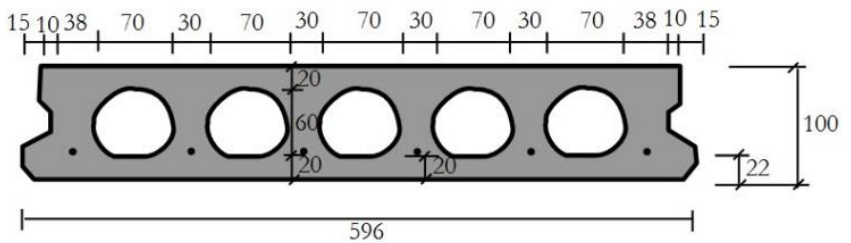

(a)

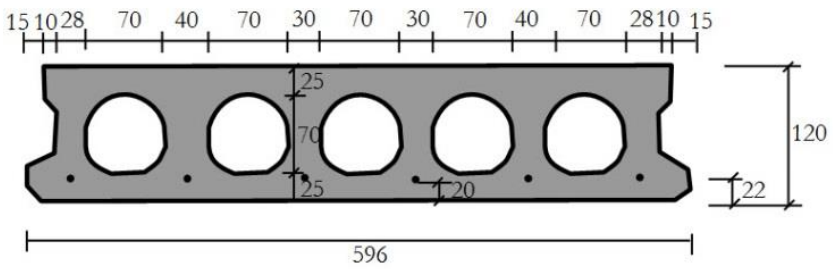

(b)

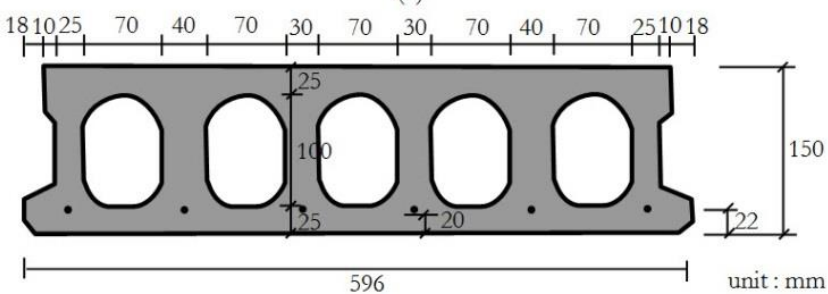

(c)

Fig. 1. Cross sections of hollow-core concrete slabs with different thicknesses: (a) $100 \mathrm{~mm}$; (b) $120 \mathrm{~mm}$; (c) $150 \mathrm{~mm}$. 


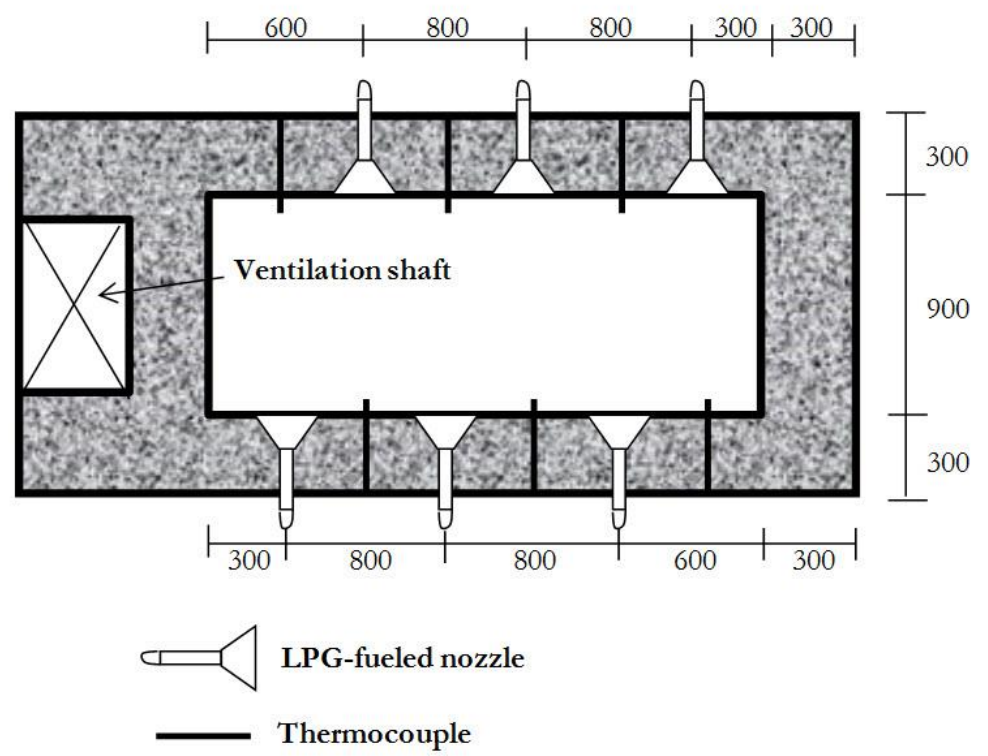

(a)

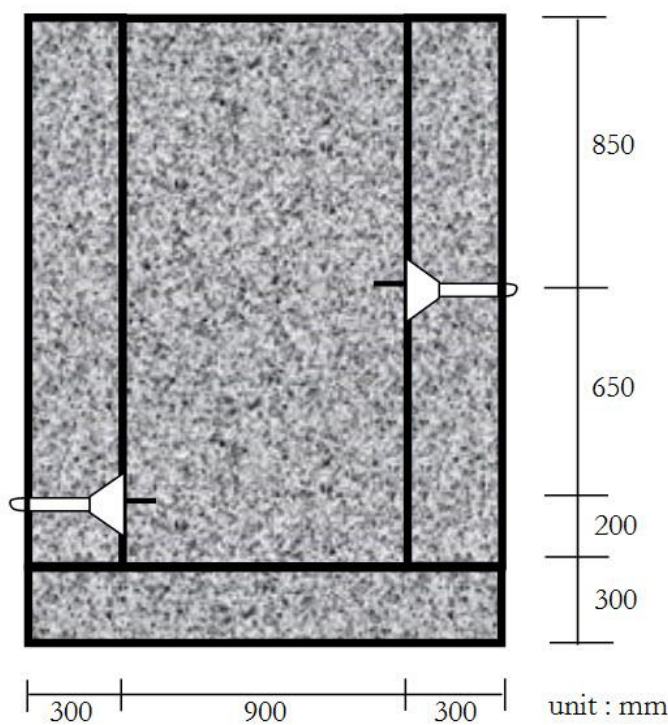

(b)

Fig. 2. Furnace chamber: (a) horizontal section (b) vertical section.

\subsubsection{Specimen installation}

All of the specimens were installed inside the furnace chamber as simply supported one-way slabs on two steel-concrete composite blocks. The seating dimensions of each specimen at both ends on the supports were specified as $200 \mathrm{~mm}$ to simulate the actual conditions of hollow-core concrete slab installation in practice. The details of the composite support are shown in Fig. 3. Note that one of the supports was manufactured with a $200 \mathrm{~mm} \times 500 \mathrm{~mm}$ opening to accommodate hot air exhaust outflow from the furnace chamber.

To ensure the exposure to heat only at the soffit of the slab during the fire test, two insulating bars were installed on both sides of the slab and ceramic fiber blankets were also used to cover the unexposed surface of the slab and the supporting concrete blocks as well as to fill any voids along the edges of the specimen. 


\subsubsection{Loading frame}

Prior to heating up the furnace chamber, each specimen was subjected to a uniformly distributed load as determined by the specified load ratio. The load was initially applied as a point load by means of a hydraulic jack with $300-\mathrm{kN}$ capacity. The applied load was transferred to the specimen using a mechanical device as shown in Fig. 4. Note that the contact points between the loading device and the specimen were allowed to rotate freely in longitudinal direction to accommodate the vertical deflection of the specimen during the fire test.

To maintain a constant level of loading with respect to the specified load ratio, a load cell was installed between the hydraulic jack and the mechanical device. Figure 5 illustrates the overview of the test setup for the fire tests.

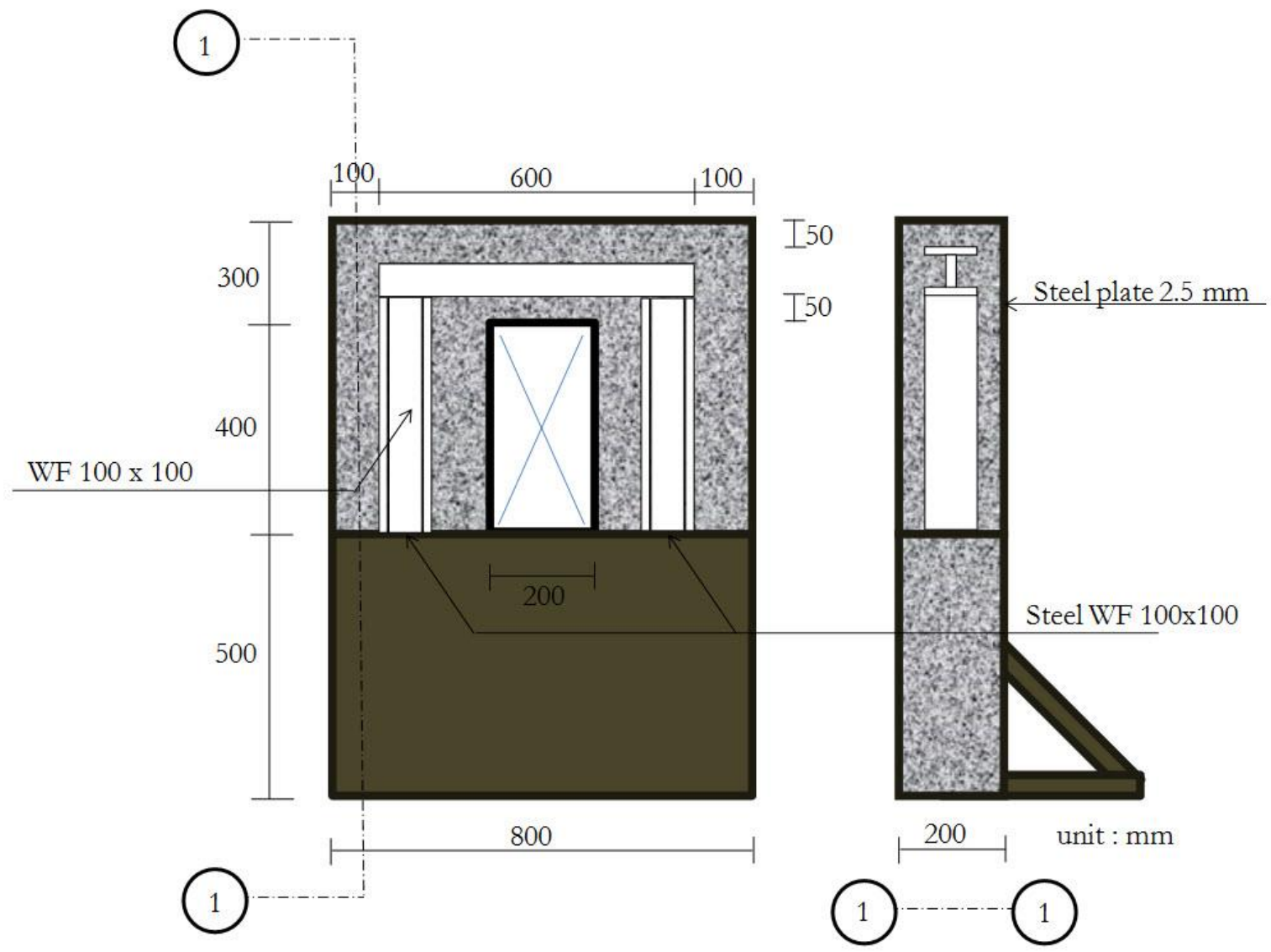

Fig. 3. Support of the test specimen with ventilation opening. 


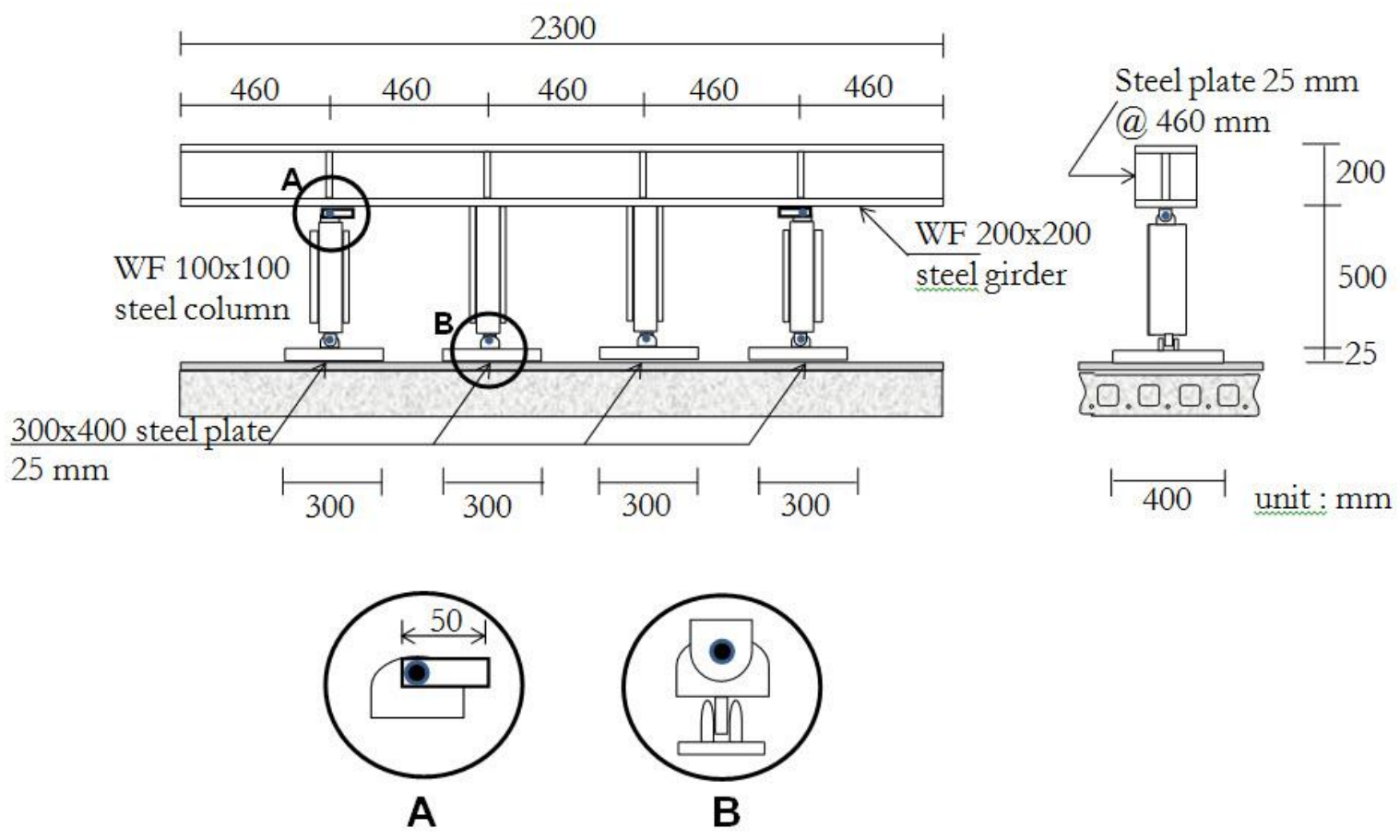

Fig. 4. Details of the loading frame.

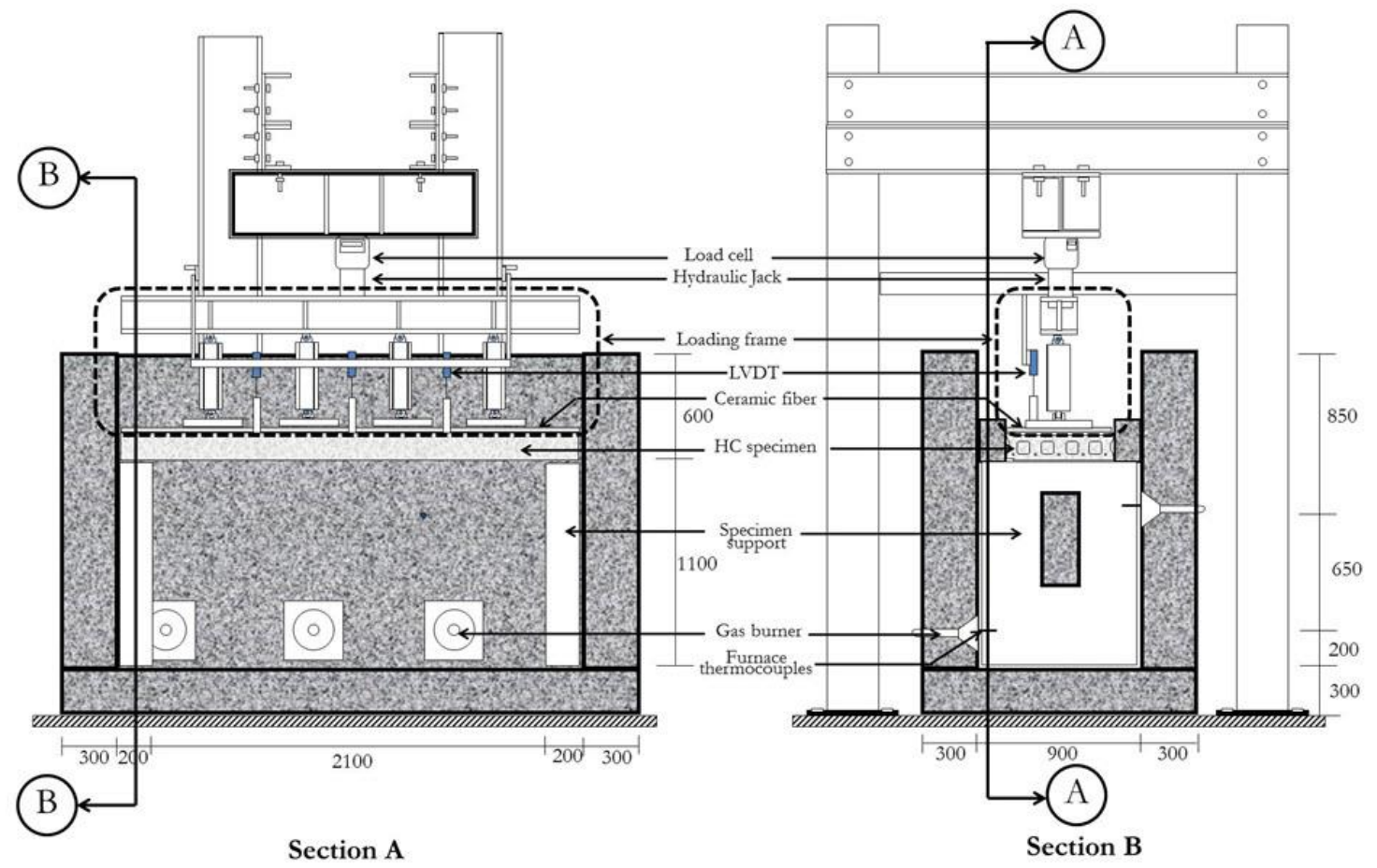

Fig. 5. Overview of the experimental setup.

\subsection{Instrumentation}

The temperatures of the hollow-core concrete slabs were measured during the fire test using type- $\mathrm{K}$ thermocouples wires installed at fourteen different locations as shown in Fig. 6. The temperature data were recorded and collected through the Kyowa EDX-100A4H data acquisition system. 

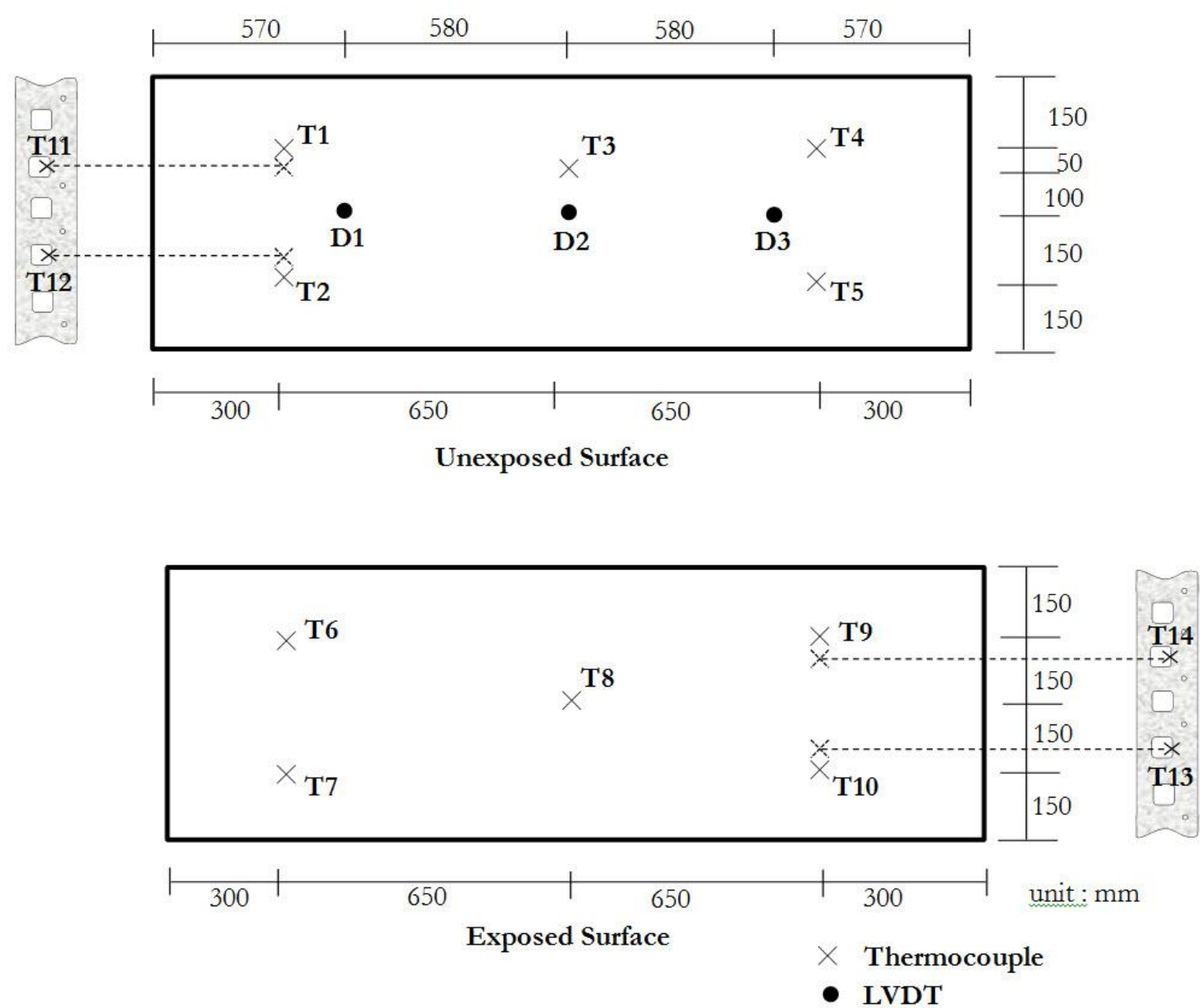

Fig. 6. Locations of thermocouples and LVDTs on the test specimen.

The vertical deflections of each hollow-core concrete slab were also recorded during the heating period using three linear variable differential transducers (LVDTs) with a measurement range of $\pm 200 \mathrm{~mm}$ at midspan and quarter-span as also shown in Fig. 6.

Post-fire investigations of the hollow-core concrete slabs were conducted to quantify the severity of concrete spalling on the exposed surface. A $50 \mathrm{~mm} \times 50 \mathrm{~mm}$ grid system was used for mapping the locations and areas of concrete spalling. The depth of concrete spalling at each grid location was also recorded.

\subsection{Test Program}

The test program can be divided into two parts. The first part (HCT1 - HCT3) investigates the effect of heat exposure time on the behavior of the hollow-core concrete slabs. The second part (HCL1 - HCL6) examines the effect of load ratio and thickness of slab on the fire-resistance performance of the hollowcore concrete slabs.

\subsubsection{Termination criteria}

As previously mentioned, the heating condition inside the furnace chamber was controlled to follow the standard heating curve of ISO 834-1, with a target heating duration for each specimen. In addition, the following criteria for structural failure of ISO 834-1 were also adopted for the termination of the fire test.

(a) Limiting deflection at $D=L^{2} / 400 d \mathrm{~mm}$; and

(b) Limiting rate of deflection at $\mathrm{d} D / \mathrm{d} t=\mathrm{L}^{2} / 9000 \mathrm{~d} \mathrm{~mm} / \mathrm{min}$, 
where $L$ is the clear span of the test specimen $(\mathrm{mm})$ and $d$ is the distance from the extreme fiber of the design compression zone to the extreme fiber of the design tensile zone of the structural section $(\mathrm{mm})$. Note that the rate of deflection criterion is applied herein regardless of the maximum value of the deflection to reflect a rapid drop of the applied load as a result of loss in load-bearing capacity of the specimen.

\subsubsection{Load ratio}

The applied load on each of the hollow-core concrete slabs was calculated in terms of the ratio between the bending moment due to the applied load and the flexural capacity of the slab at normal temperature determined according to ACI 318-11 [9]. Two values of load ratios, 0.3 and 0.6, are adopted for the current study.

\section{Results and Discussions}

\subsection{Effect of Heating Duration}

The test results for HCT1 - HCT3 are summarized in Table 2. The measured temperatures and vertical deflections of the specimens during the fire tests are plotted in Fig. 7 and Fig. 8, respectively.

HCT1 was subjected to the applied load ratio of 0.3 . During the 30 -min heating period, the average temperature of the exposed surface reached $712^{\circ} \mathrm{C}$. The temperature gradients between the exposed and unexposed surfaces and between the exposed surface and hollow core after 30 min were $662^{\circ} \mathrm{C}$ and $568^{\circ} \mathrm{C}$, respectively. The maximum vertical deflection of the specimen was $23.7 \mathrm{~mm}$ at mid-span after the 30 -min heat exposure. The slab remained intact without collapse. No concrete spalling was observed on the exposed surface of the specimen as shown in Fig. 9.

HCT2 was also subjected to the applied load ratio of 0.3 as HCT1 but was heated for 60 min. After the 60-min heating period, the maximum vertical deflection recorded at mid-span was $31.4 \mathrm{~mm}$ while the average temperature of the exposed surface was $867^{\circ} \mathrm{C}$. The temperature gradients between the exposed and unexposed surfaces and between the exposed surface and hollow core after 60 min were $762^{\circ} \mathrm{C}$ and $573^{\circ} \mathrm{C}$, respectively. The post-fire investigation of HCT2 revealed that $77 \%$ of the exposed surface area was subject to concrete spalling with an average depth of $2 \mathrm{~mm}$. In addition, a transverse crack was observed near mid-span as shown in Fig. 10. However, the specimen did not collapse during the fire test.

Table 2. Summary of test results for HCT1-HCT3.

\begin{tabular}{|c|c|c|c|c|c|}
\hline \multirow[t]{2}{*}{ Specimen } & \multirow{2}{*}{$\begin{array}{l}\text { Heating } \\
\text { duration } \\
\text { (min) }\end{array}$} & \multirow{2}{*}{$\begin{array}{l}\text { Maximum vertical } \\
\text { deflection } \\
(\mathrm{mm})\end{array}$} & \multicolumn{3}{|c|}{ Concrete spalling } \\
\hline & & & $\begin{array}{c}\text { Area } \\
(\%)\end{array}$ & $\begin{array}{l}\text { Maximum depth } \\
(\mathrm{mm})\end{array}$ & $\begin{array}{l}\text { Average depth } \\
\text { (mm) }\end{array}$ \\
\hline HCT1 & 30 & 23.7 & 0 & - & - \\
\hline HCT2 & 60 & 31.4 & 77 & 3.0 & 2.0 \\
\hline НСТ3 & 82 & 57.5 & 100 & 10.0 & 5.0 \\
\hline
\end{tabular}




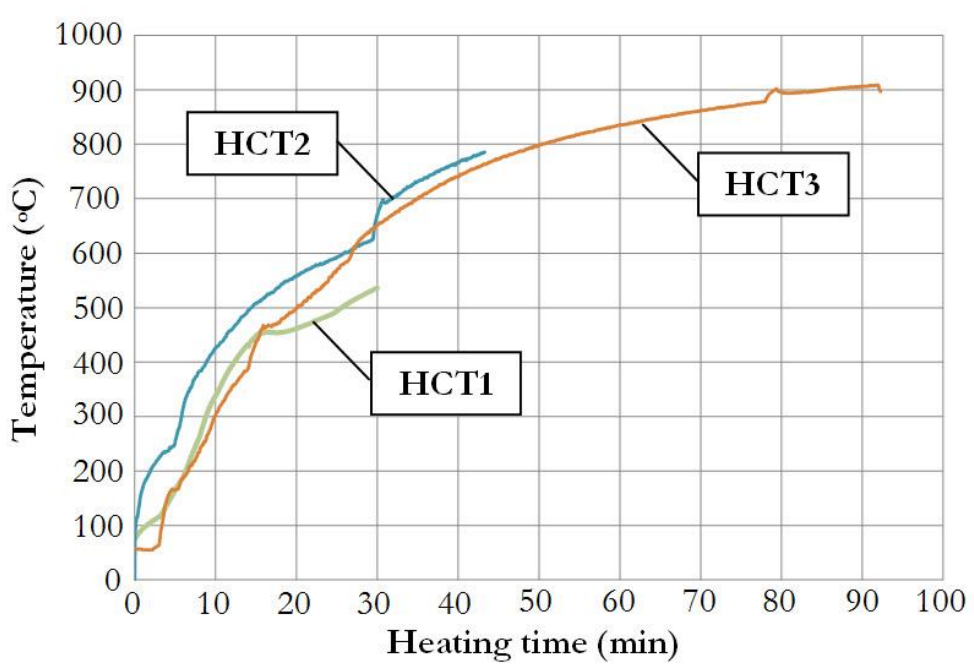

(a)

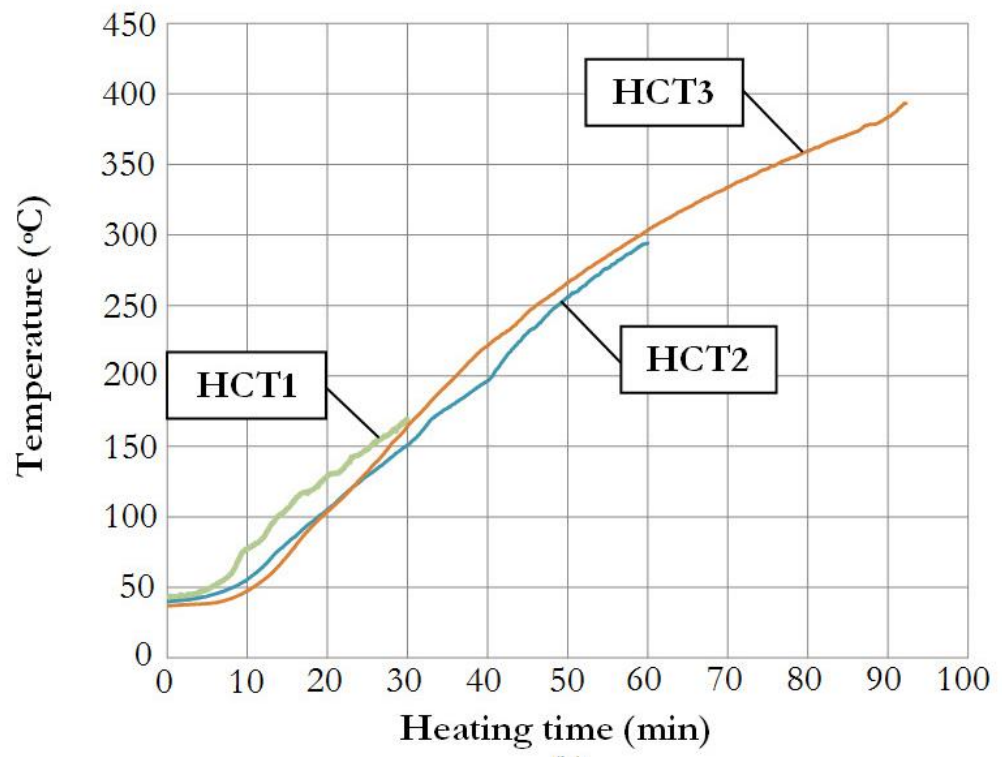

(b)

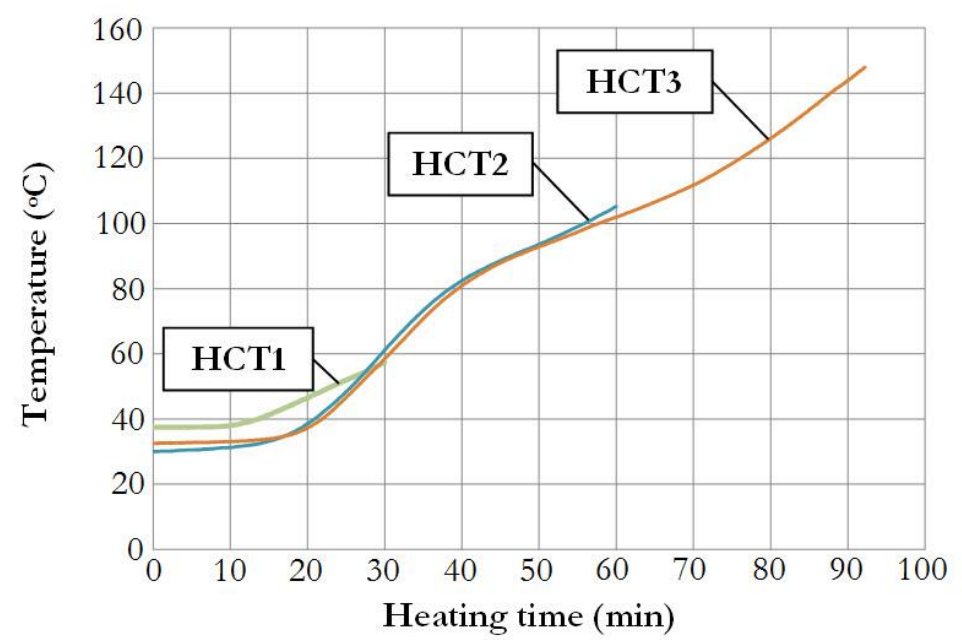

(c)

Fig. 7. Temperature vs. time for HCT1-HCT3: (a) exposed surface (b) hollow core (c) unexposed surface. 


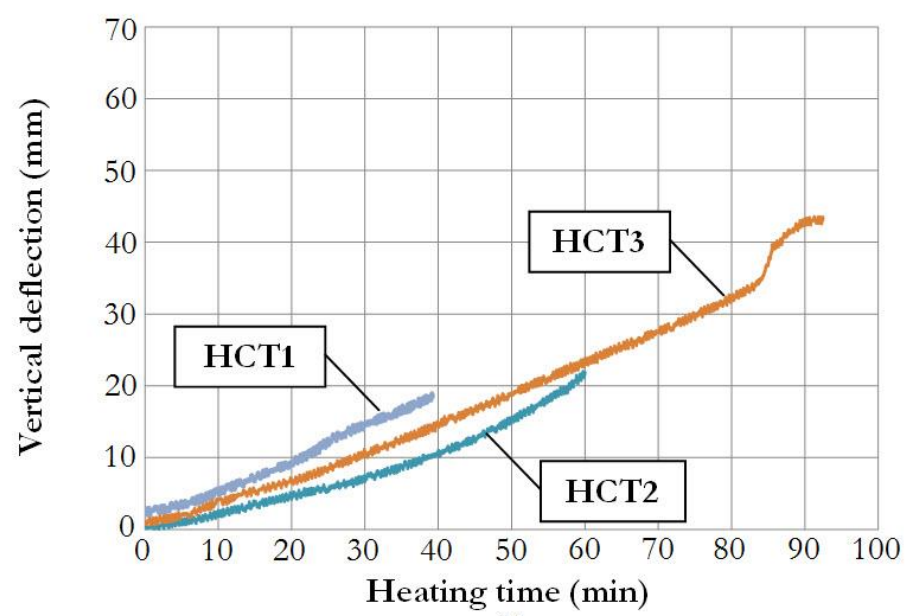

(a)

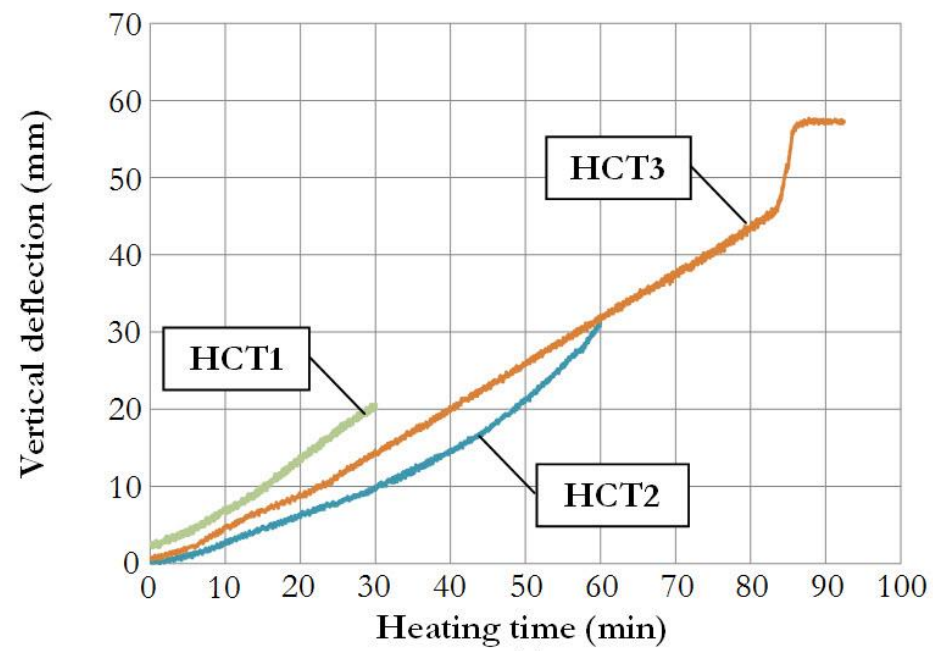

(b)

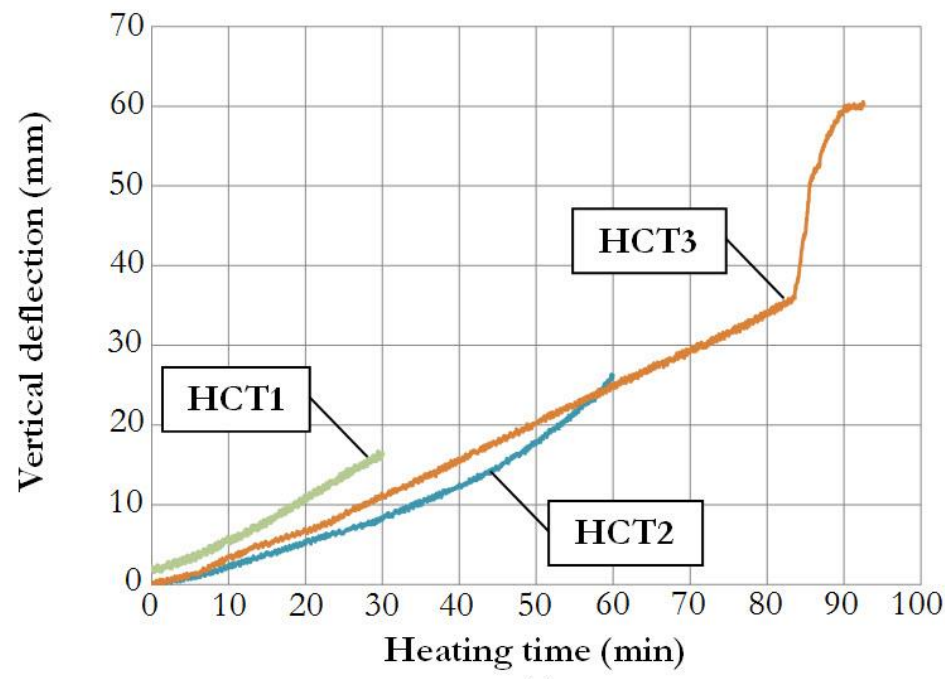

(c)

Fig. 8. Vertical deflection vs. time for HCT1 - HCT3: (a) $1^{\text {st }}$ quarter (b) mid-span (c) $3^{\text {rd }}$ quarter. 


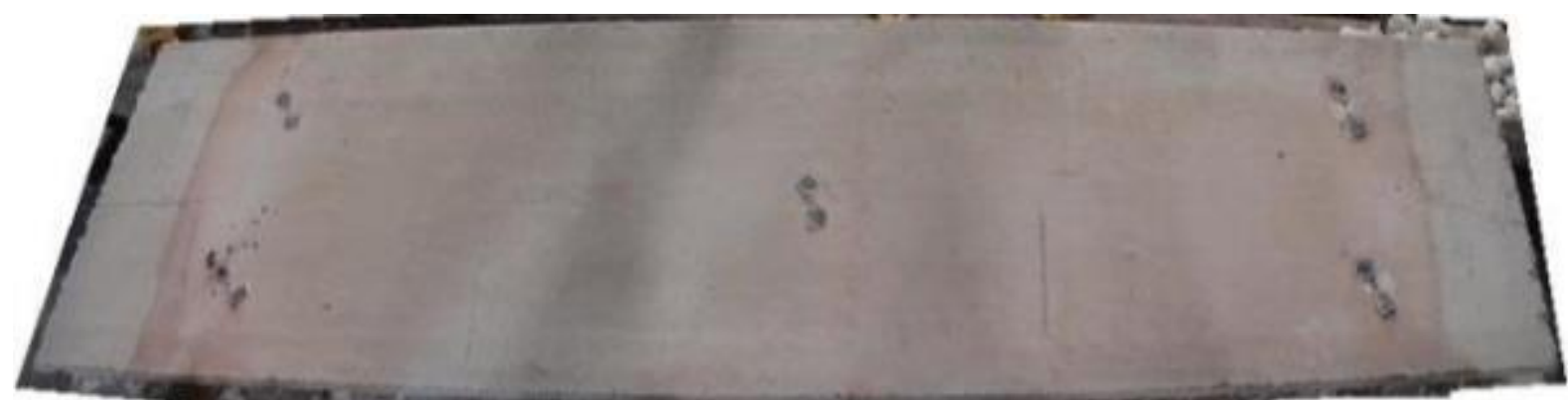

Fig. 9. HCT1 after fire test.

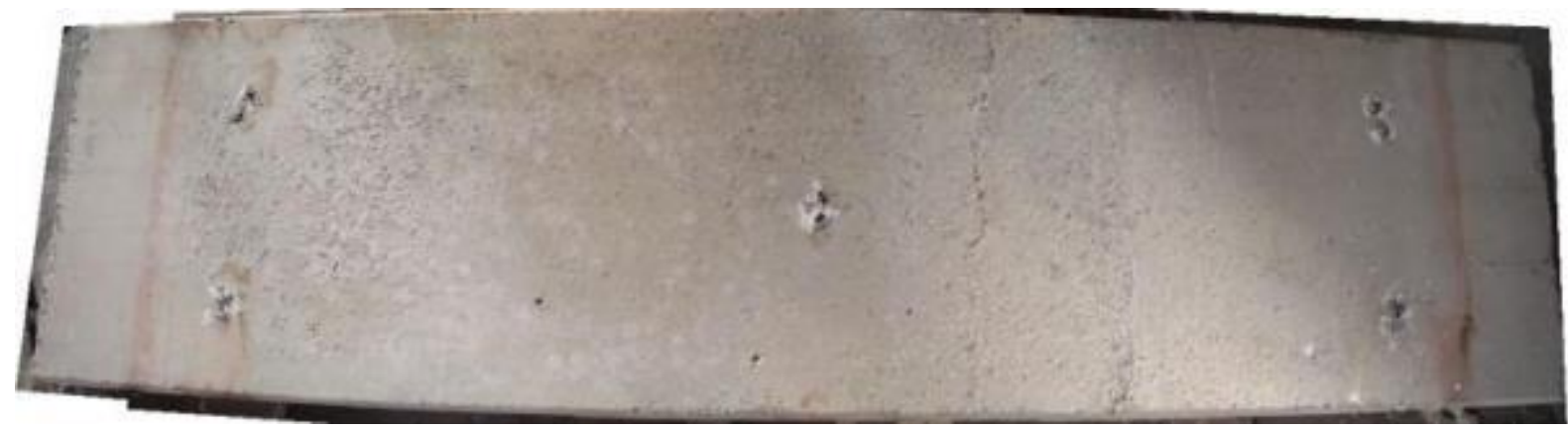

Fig. 10. HCT2 after fire test.

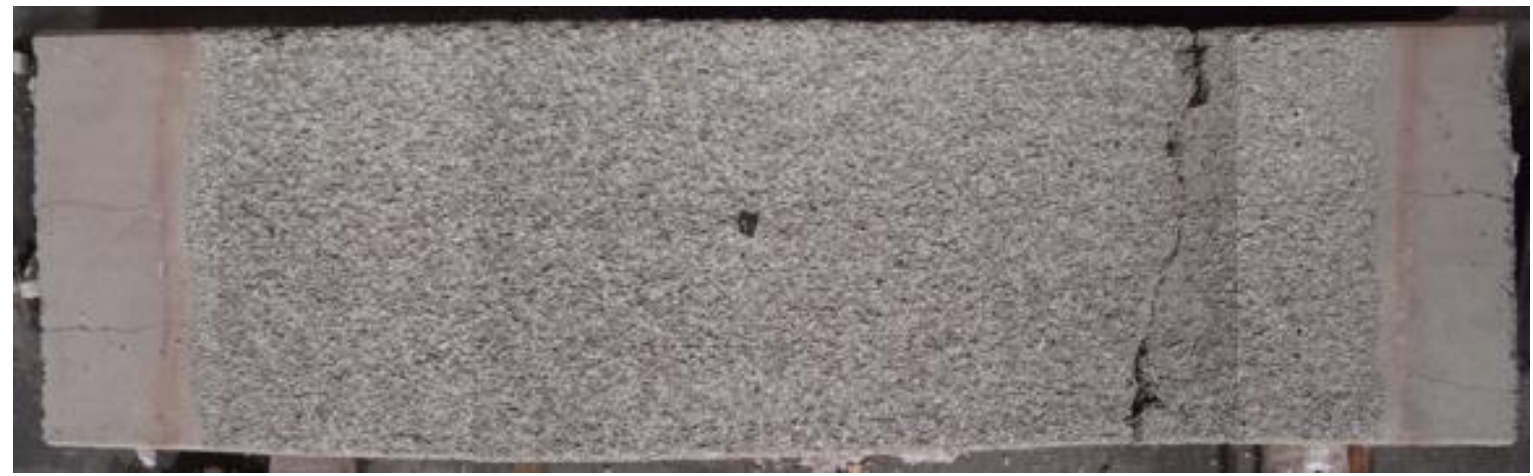

Fig. 11. HCT3 after fire test.

For HCT3 the heating duration was specified as $90 \mathrm{~min}$. However, the specimen collapsed after $82 \mathrm{~min}$ of heat exposure based on the rate of deflection criterion of ISO 834-1. The maximum deflection recorded at mid-span was $57.5 \mathrm{~mm}$ and the average temperature of the exposed surface reached $907^{\circ} \mathrm{C}$ after the 82 min heating period. The temperature gradients between the exposed and unexposed surfaces and between the exposed surface and hollow core after $82 \mathrm{~min}$ were $759^{\circ} \mathrm{C}$ and $514^{\circ} \mathrm{C}$, respectively. The post-fire investigation revealed a transverse crack on the exposed surface near the support as shown in Fig. 11. Furthermore, the entire exposed surface area of the specimen was subject to concrete spalling with an average depth of $10 \mathrm{~mm}$.

Based on the test results, it can be concluded that the level of concrete spalling increases with the heating duration. However, concrete spalling may not be a crucial factor to the failure of the specimen since the maximum depth of concrete spalling for HCT3 is less than the concrete cover. The failure of HCT3 is observed to be due to the occurrence of a transverse crack after $82 \mathrm{~min}$ of standard fire exposure.

\subsection{Effect of Thickness of Slab and Load Ratio}

The heating duration for HCL1 - HCL6 was specified as the time until failure of each specimen, and is reported as the fire-resistance rating (FRR) as summarized in Table 3. The temperatures and vertical deflections of the specimens recorded during the fire tests are illustrated in Fig. 12 and Fig. 13, respectively.

HCL1 was tested until collapse under the specified load ratio of 0.3. Failure of the specimen was due to the rate of deflection criterion after $107 \mathrm{~min}$ of heat exposure. The maximum vertical deflection recorded at 
mid-span was $140.3 \mathrm{~mm}$ and the average temperature of the exposed surface was $963^{\circ} \mathrm{C}$ at the time of failure. The temperature gradients between the exposed and unexposed surfaces and between the exposed surface and hollow core after $107 \mathrm{~min}$ were $719^{\circ} \mathrm{C}$ and $503^{\circ} \mathrm{C}$, respectively. From the post-fire examination, it was found that concrete spalling occurred over the entire exposed area with an average depth of $10 \mathrm{~mm}$ and a maximum depth of $15 \mathrm{~mm}$. A large transverse crack was also observed near mid-span as shown in Fig. 14.

HCL2 had the same thickness as HCL1 $(100 \mathrm{~mm})$ but was subjected to a higher load ratio of 0.6. The FRR of the specimen was $53 \mathrm{~min}$ based on the rate of deflection criterion with a maximum vertical deflection recorded at mid-span of $91 \mathrm{~mm}$, which was smaller compared with HCL1. The average temperature of the exposed surface reached $812^{\circ} \mathrm{C}$ at the time of failure. The temperature gradients between the exposed and unexposed surfaces and between the exposed surface and hollow core after the 53 -min heating period were $704^{\circ} \mathrm{C}$ and $539^{\circ} \mathrm{C}$, respectively. Despite a higher load ratio compared with HCL1, concrete spalling was observed on only $84 \%$ of the exposed area with an average depth of $3 \mathrm{~mm}$ and a maximum depth of $5 \mathrm{~mm}$. In terms of concrete spalling, the severity of damage was much lower compared with HCL1. Nevertheless, the post-fire investigation revealed a transverse crack near mid-span on the exposed surface as shown in Fig. 15.

The thickness of HCL3 was $120 \mathrm{~mm}$ and the load ratio was specified as 0.3 . The test results can be cross checked with HCT3. It was found that the FRR of HCL3 was 91 min based on the rate of deflection criterion. The FRR of HCL3 is a bit higher compared with HCT3 at 82 min. The average temperature of the exposed surface reached $930^{\circ} \mathrm{C}$ at the time of failure. The temperature gradients between the exposed and unexposed surfaces and between the exposed surface and hollow core after the 91 -min heating period were $813^{\circ} \mathrm{C}$ and $640^{\circ} \mathrm{C}$, respectively. The maximum vertical deflection recorded at mid-span was $58.1 \mathrm{~mm}$. Even though the entire exposed area of the specimen was subject to concrete spalling with an average depth of $7.5 \mathrm{~mm}$ and a maximum depth of $10 \mathrm{~mm}$, no evidence of transverse crack was observed after the fire test as can be seen in Fig. 16.

The thickness of HCL4 was the same as HCL3 but the load ratio was higher at 0.6. The FRR of the specimen was $33 \mathrm{~min}$ based on the rate of deflection criterion. After the 33-min heating period, the maximum vertical deflection recorded at mid-span was $38.8 \mathrm{~mm}$ and the average temperature of the exposed surface was $744^{\circ} \mathrm{C}$. The temperature gradients between the exposed and unexposed surfaces and between the exposed surface and hollow core after the 33 -min heating period were $673^{\circ} \mathrm{C}$ and $608^{\circ} \mathrm{C}$, respectively. Interestingly, virtually no concrete spalling was observed on the exposed surface of the specimen after the fire test. However, a severe transverse crack was observed near the support as shown in Fig. 17. Note that the longitudinal crack at the support was an extraneous damage as a result of hoisting the specimen which occurred after the fire test.

Table 3. Summary of test results for HCL1-HCL6.

\begin{tabular}{cccccc}
\hline Specimen & $\begin{array}{c}\text { FRR } \\
\text { (min) }\end{array}$ & $\begin{array}{c}\text { Maximum vertical } \\
\text { deflection } \\
(\mathbf{m m})\end{array}$ & $\begin{array}{c}\text { Area } \\
\mathbf{( \% )}\end{array}$ & $\begin{array}{c}\text { Maximum depth } \\
\mathbf{( m m})\end{array}$ & $\begin{array}{c}\text { Average depth } \\
\text { ( mm) }\end{array}$ \\
\hline HCL1 & 107 & 140.3 & 100 & 15.0 & 10.0 \\
HCL2 & 53 & 91.0 & 84 & 5.0 & 3.0 \\
HCL3 & 91 & 58.1 & 100 & 10.0 & 7.5 \\
HCL4 & 33 & 38.8 & 0 & - & - \\
HCL5 & 66 & 51.2 & 85 & 7.5 & 2.5 \\
HCL6 & 39 & 40.7 & & no measurements due to brittle failure \\
\hline
\end{tabular}




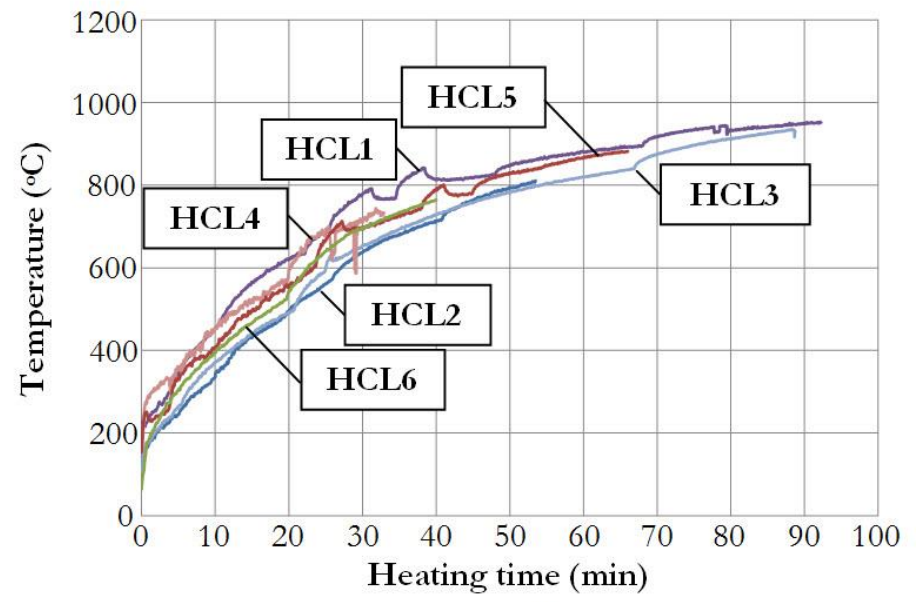

(a)

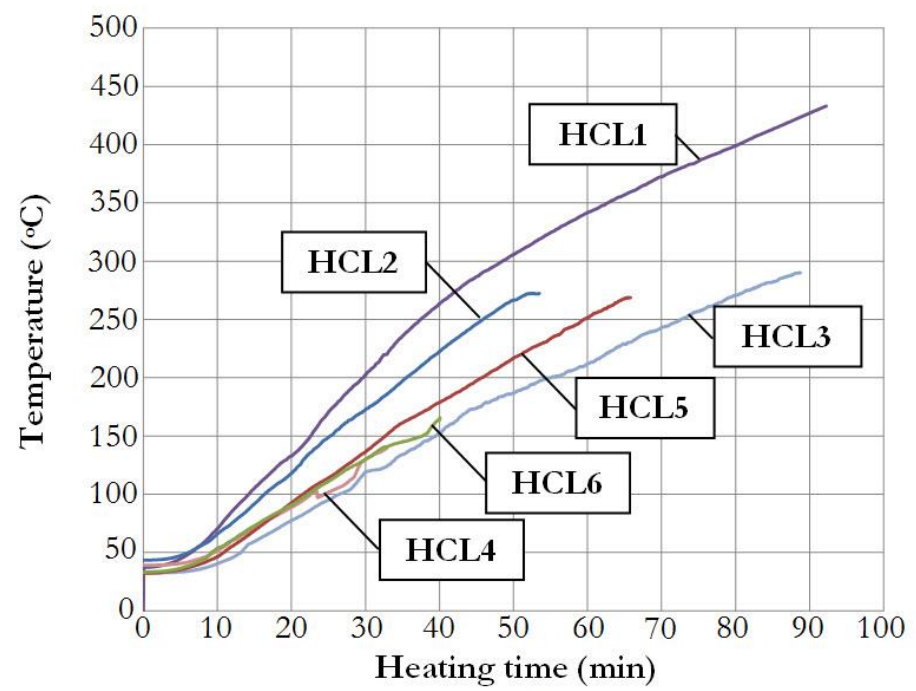

(b)

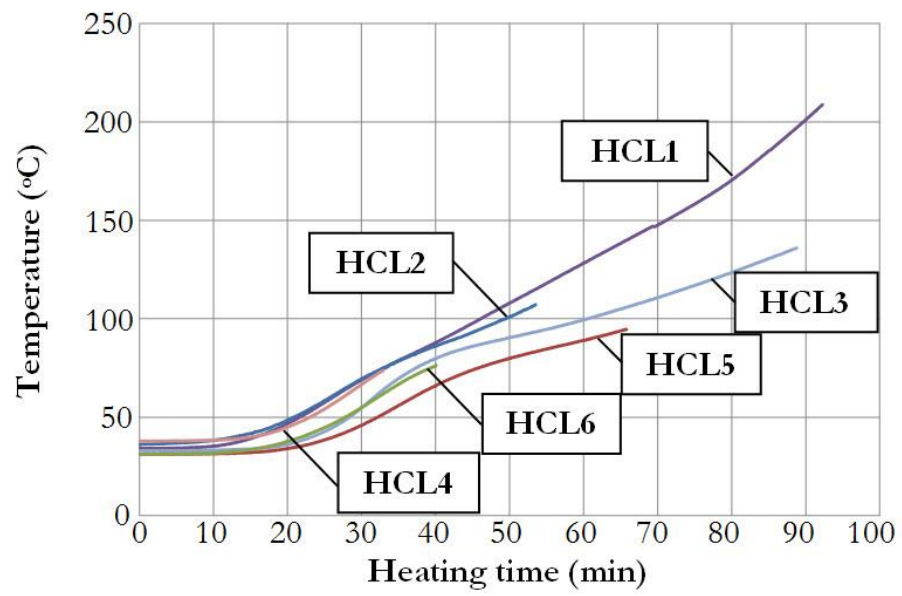

(c)

Fig. 12. Temperature vs. time for HCL1 - HCT6: (a) exposed surface (b) hollow core (c) unexposed surface. 


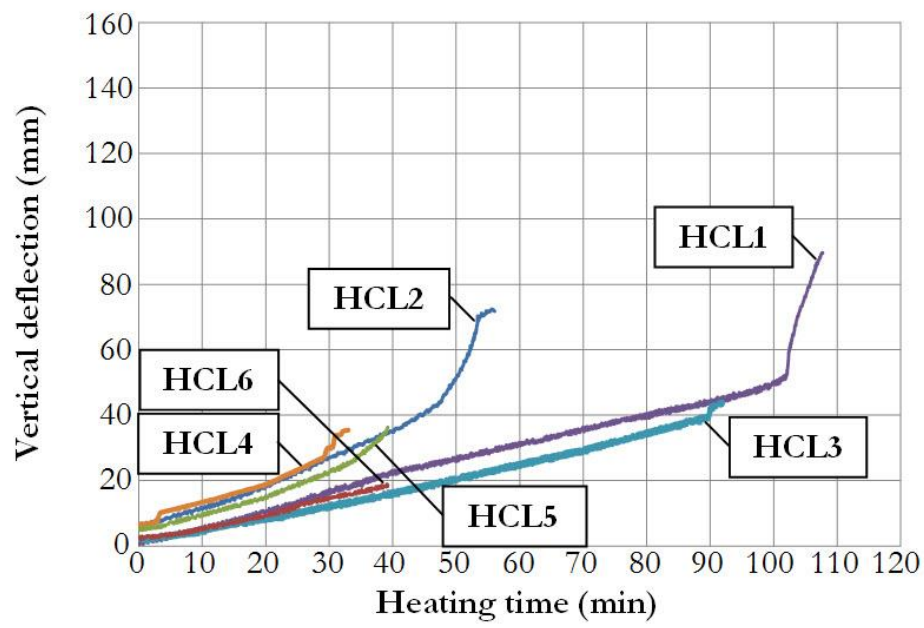

(a)

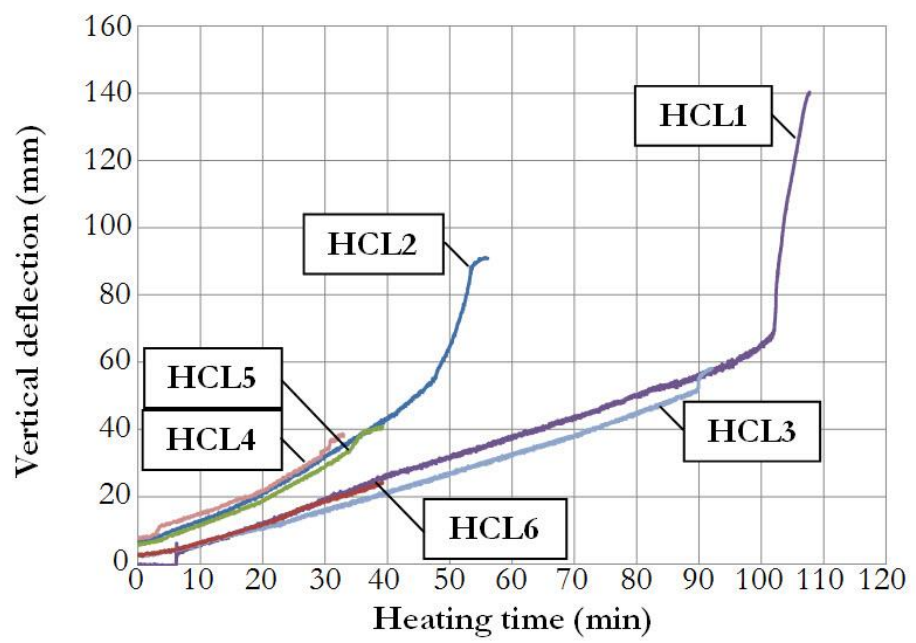

(b)

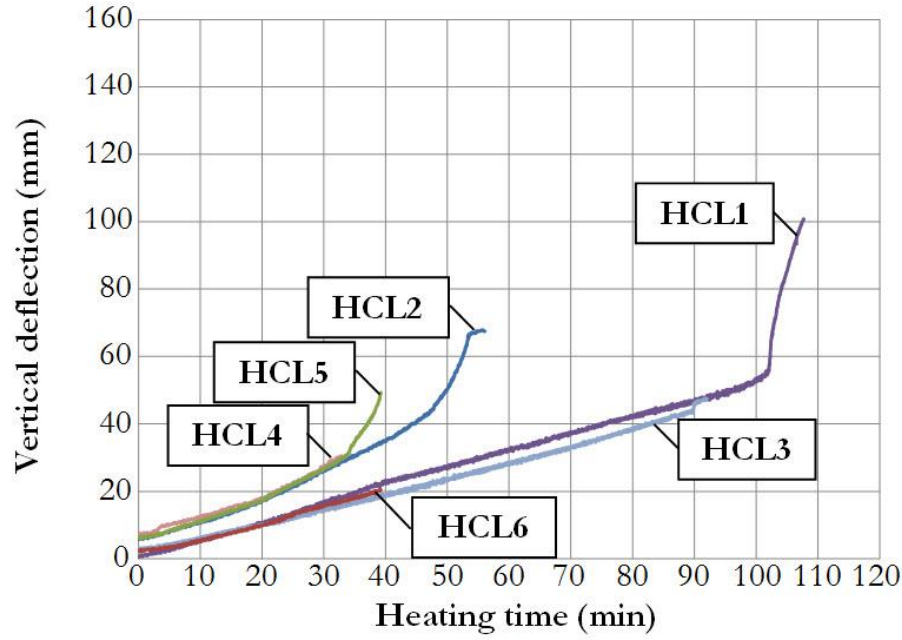

(c)

Fig. 13. Vertical deflection vs. time for HCL1 - HCL6: (a) $1^{\text {st }}$ quarter (b) mid-span (c) $3^{\text {rd }}$ quarter. 


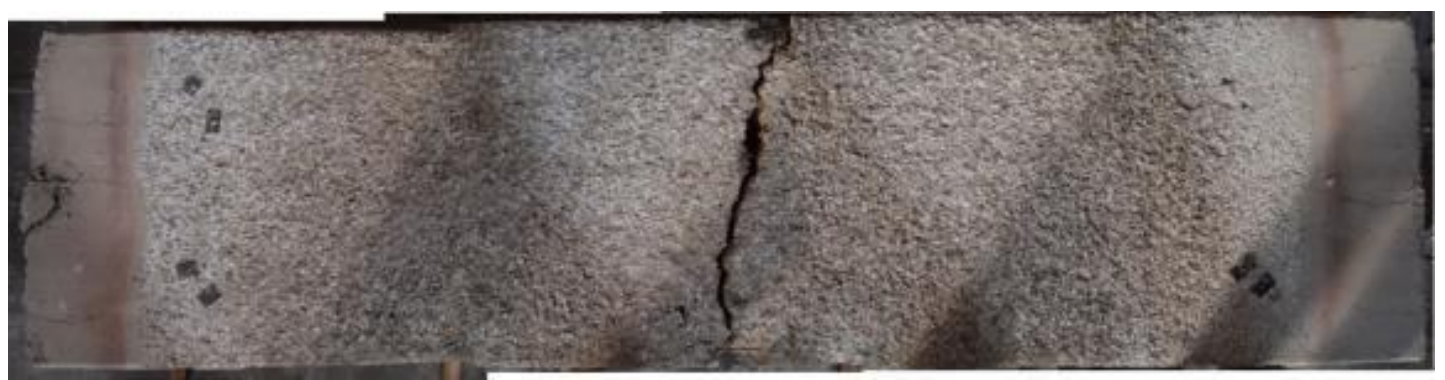

Fig. 14. HCL1 after fire test.

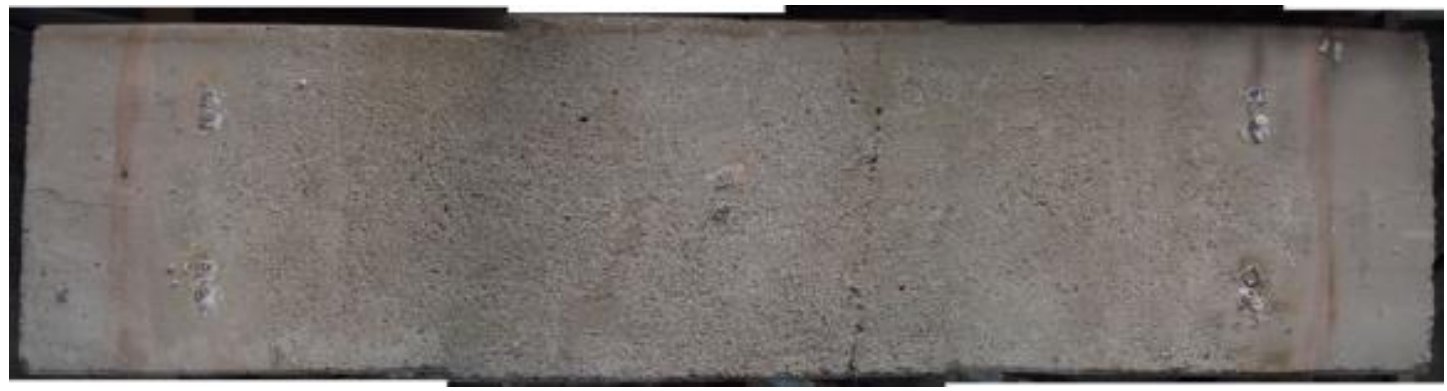

Fig. 15. HCL2 after fire test.

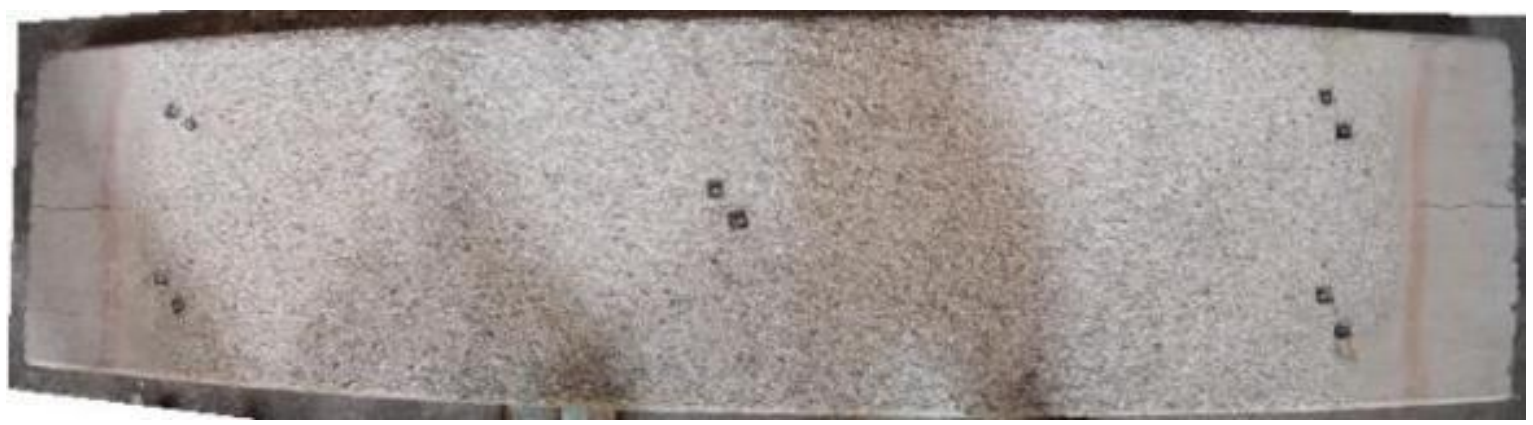

Fig. 16. HCL3 after fire test.

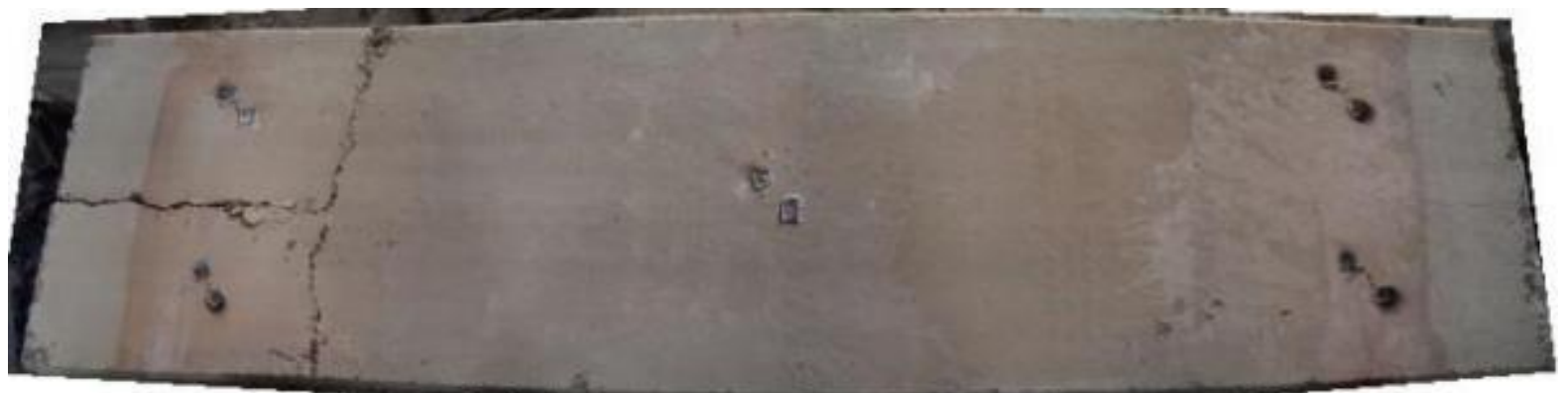

Fig. 17. HCL4 after fire test.

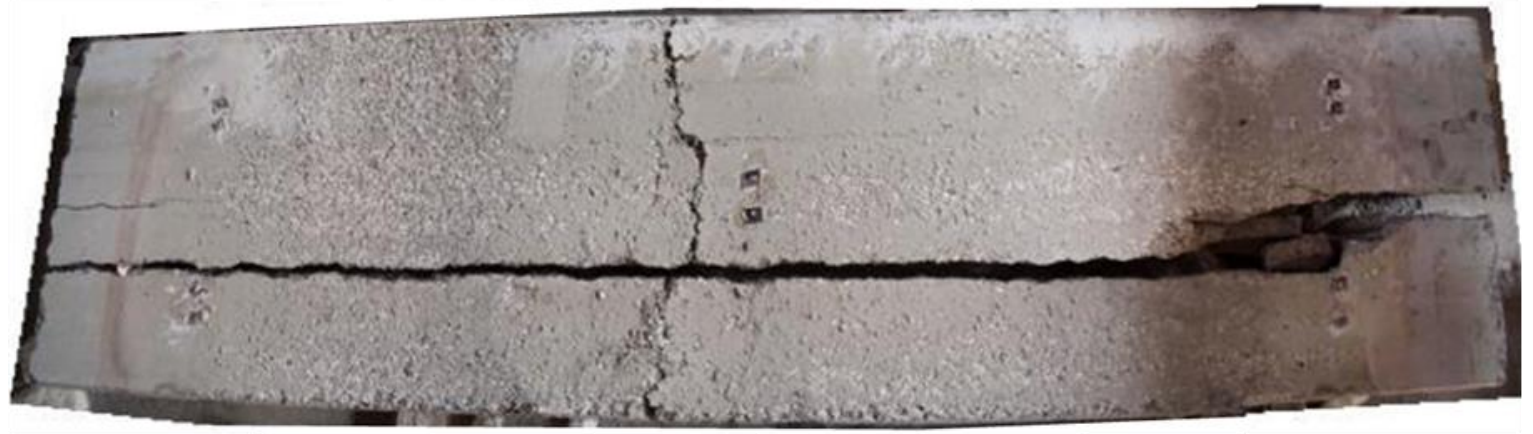

Fig. 18. HCL5 after fire test. 

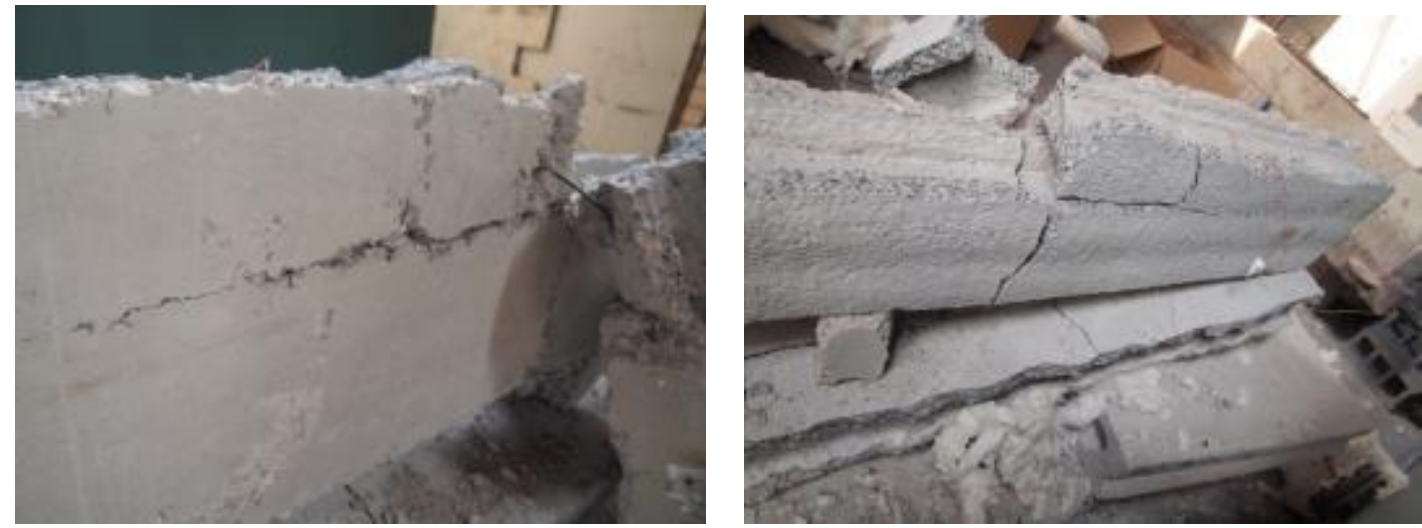

Fig. 19. HCL6 after fire test.

The thickness of HCL5 was $150 \mathrm{~mm}$, while the load ratio was specified as 0.3 . The FRR of the specimen was $66 \mathrm{~min}$ based on the rate of deflection criterion. The maximum vertical deflection recorded after the 66-min heating duration was $51.2 \mathrm{~mm}$, which occurred at the first quarter. The average temperature of the exposed surface of the specimen was $882^{\circ} \mathrm{C}$ at the time of failure. The temperature gradients between the exposed and unexposed surfaces and between the exposed surface and hollow core after the 66 -min heating period were $788^{\circ} \mathrm{C}$ and $614^{\circ} \mathrm{C}$, respectively. Based on the post-fire examination, a transverse crack was observed near mid-span on the exposed surface while the longitudinal crack was an extraneous damage as a result of hoisting the specimen which occurred after the fire test. Concrete spalling was observed over $85 \%$ of the exposed surface area with an average depth of $2.5 \mathrm{~mm}$ and a maximum depth of $7.5 \mathrm{~mm}$. Fig. 18 illustrates HCL5 after the fire test.

HCL6 had the same thickness as HCL5 but was subjected to a higher load ratio at 0.6. Surprisingly, the specimen abruptly collapsed after only 39 min of heat exposure without any significant warning. Fig. 19 illustrates the remaining HCL6 after failure. No significant measurements could be taken due to the brittle failure. The average temperature of the exposed surface prior to failure was $764^{\circ} \mathrm{C}$ while the maximum vertical deflection recorded at mid-span was $40.7 \mathrm{~mm}$. The temperature gradients between the exposed and unexposed surfaces and between the exposed surface and hollow core prior to failure were $688^{\circ} \mathrm{C}$ and $600^{\circ} \mathrm{C}$, respectively. The post-fire investigation of damage revealed tendon rupture as well as transverse and longitudinal cracks on the exposed surface. Longitudinal cracks were also observed along the web of the hollow cores.

Based on the test results, it can be concluded that even though smaller vertical deflections are induced in thicker hollow-core concrete slabs, the FRRs may be lower. This result may be seen counter-intuitive in that thicker reinforced concrete slabs are generally designated with higher FRRs [10-12]. However, the situation is different for relatively thin hollow-core concrete slabs where the core configuration varies for slabs with different thicknesses. By comparing the specimens with the same thickness but with different load ratios, it is seen that the higher load ratio leads to a more rapid collapse. The post-fire investigations also reveal that the failure of the specimens is mainly due to the occurrence of a transverse crack on the exposed surface. Furthermore, the level of concrete spalling is not significantly affected by the thickness of slab and the load ratio.

It is also important to point out that, based on the test results, the FRRs of all of the specimens fall below the minimum requirements of $120 \mathrm{~min}$ as specified in the current building regulations of Thailand. It is therefore recommended that further studies be conducted on supplementary means of fire protection for hollow-core concrete slabs in practical building construction.

\section{Conclusions}

An experimental study was conducted to examine the fire resistance of relatively thin hollow-core concrete slabs with simple supports through a series of fire tests in accordance with ISO 834 standard. Based on the test results, it has been found that the fire-resistance ratings of all the tested specimens fall below the specified requirements in the current building regulations of Thailand. The level of concrete spalling on the fire-exposed surface increases with the heating duration. It has also been found that the fire resistance of 
thicker hollow-core concrete slabs may be lower, even when smaller values of maximum vertical deflection are observed during the heating period. Furthermore, a higher load ratio leads to a more rapid collapse of the tested specimen. The experimental results suggest the necessity of supplementary means of fire protection for these slabs in practical building construction. It should also be noted that the hollow-core slab installation in practice may incorporate topping concrete (about $50 \mathrm{~mm}$ thick with temperature steel). Further investigations should be conducted to investigate the effects of the topping concrete on the fireresistance performance of the hollow-core concrete slabs.

\section{Acknowledgements}

This research is financially supported by the Rachadaphiseksomphot Endowment Fund Part of the "Stengthen CU's Researcher's Project." The support is gratefully acknowledged.

\section{References}

[1] W. Z. Zheng, X. M. Hou, D. S. Shi, and M. X. Xu, "Experimental study on concrete spalling in prestressed slabs subjected to fire," Fire Saf J, vol. 45, pp. 283-297, 2010.

[2] C. G. Bailey and E. Ellobody, "Fire tests on bonded post-tensioned concrete slabs," Eng Struct, vol. 31, pp. 686-696, 2009.

[3] E. Ellobody and C. G. Bailey, "Modelling of unbonded post-tensioned concrete slabs under fire conditions," Fire Saf J, vol. 44, pp. 159-167, 2009.

[4] J. Gales, L. A. Bisby, and M. Gillie, "Unbonded post tensioned concrete in fire: A review of data from furnace tests and real fires, " Fire SafJ, vol. 46, pp. 151-163, 2011.

[5] L. Lim, A. H. Buchanan, and P. J. Moss, "Restraint of fire-exposed concrete floor systems," Fire Mater, vol. 28, pp. 95-125, 2004.

[6] J. Chang, A. H. Buchanan, R. P. Dhakal, and P. J. Moss, "Hollow-core concrete slabs exposed to fire," Fire Mater, vol. 32, pp. 321-331, 2008.

[7] J. Fellinger, J. Stark, and J. Walraven, "Shear and anchorage behavior of fire exposed hollow core slabs,” Heron, vol. 50, no. 4, pp. 279-301, 2005.

[8] International Organization for Standardization, ISO 834-1 Fire Resistance Tests - Elements of Building Construction, Part 1: General Requirements, 1999.

[9] American Concrete Institute, ACI 318M-11 Building Code Requirements for Structural Concrete, 2011.

[10] American Concrete Institute, ACI 216.1M-07/TMS-216-07 Code Requirements for Determining Fire Resistance of Concrete and Masonry Construction Assemblies, 2007.

[11] American Society of Civil Engineers, ASCE/SEI/SFPE 29-05 Standard Calculation Methods for Structural Fire Protection, 2005.

[12] Comité Européen de Normalisation/British Standards Institution, EN 1992-1-2 Eurocode 2: Design of Concrete Structures. Part 1.2: General Rules - Structural Fire Design, 2004. 
